\title{
A EMERGÊNCIA DA LÍQUIDA LATERAL /L/ NA FALA DE UMA CRIANÇA: UMA ANÁLISE LONGITUDINAL
}

Tayse Feliciano Marques

(UFSC)

lzabel Christine Seara

(UFSC/CNPq)

Cristiane Lazzarotto-Volcão

(UFSC)

RESUMO

Neste trabalho, é investigada, quantitativa e qualitativamente, a emergência da líquida lateral /1/ na fala de uma criança acompanhada longitudinalmente entre 1:9 (um ano e nove meses) e 2:4 (dois anos e quatro meses). Para tanto, foram analisadas trinta e quatro produções relacionadas à palavra /eS'trela/ e verificaram-se cinco variantes de realização, sendo elas: ['tee], ['teje] ['tejle], ['teK̋] e ['tele]. Cada uma dessas variantes foi analisada qualitativamente, com base na trajetória dos formantes e na intensidade (energia) dos sons exibida nos espectrogramas, e quantitativamente, por meio da análise dos valores das frequências dos formantes e, sobretudo, através da diferença entre F2-F1, necessária à verificação do grau de posteriorização das laterais produzidas. A partir das análises dos formantes, foram constatadas produções intermediárias e gradientes na fala do sujeito na tentativa de aproximar-se do alvo - a lateral alveolar. Essas gradiências só puderam ser verificadas com base nas análises acústicas aqui detalhadas. Os valores resultantes da diferença entre F2-F1 nos auxiliaram na observação da produção do som-alvo, pois verificou-se que, quando a diferença entre esses dois formantes diminui, as produções aproximam-se da lateral alveolar. PALAVRAS-CHAVE: Fonética. Fonologia. Aquisição da linguagem. 


\section{1 lntrodução}

Considera-se concluído o processo típico de aquisição fonético-fonológica de determinado segmento quando a criança o produz de acordo com o alvo adulto, em pelo menos $75 \%$ das tentativas (YAVAS, HERNANDORENA e LAMPRECHT, 1990). Até que isso ocorra, porém, é comum o emprego de estratégias de reparo no lugar do segmento ainda não dominado.

Em relação à lateral alveolar /1/, objeto deste estudo, a literatura descreve que sua aquisição é mais tardia se comparada às classes das plosivas e das fricativas. Para Matzenauer-Hernandorena (1990), por exemplo, a aquisição de /1/ em onset absoluto ocorre aos 2:10 e em onset medial aos 2:4. Já para Mezzomo e Ribas (2004), a aquisição da lateral alveolar ocorre aos 3:0, em ambas as posições.

À vista disso, portanto, até que ocorra a aquisição plena de /1/, é comum as crianças valerem-se de estratégias de reparo, como a substituição, a semivocalização e a omissão. Com uma análise apenas de oitiva, no entanto, nem sempre é possível perceber de forma clara qual processo de reparo a criança empregou no lugar do alvo, já que nossos ouvidos muitas vezes não são capazes de captar determinados detalhes acústicos, de modo que, julgar auditivamente a produção da criança, em alguns casos, não parece ser o método mais adequado. Ademais, no processo de aquisição fonológica, é comum haver a presença, na fala da criança, do que estudiosos da área denominam de contrastes encobertos, ou seja, podem ser verificadas produções intermediárias e gradientes que se assemelham ao padrão adulto, porém não são identificadas como tal (BROWMAN e GOLDSTEIN, 1989; SILVA, 2002; BERTI, 2010 BERTI e MARINO, 2011). Essas gradiências são imperceptíveis auditivamente, mas detectáveis acústica e/ou articulatoriamente (BERTI, 2010).

A análise acústica é, portanto, uma excelente ferramenta para detectar detalhes que evidenciam as gradiências na fala infantil. Com ela, além de ser possível caracterizar de maneira objetiva a produção de um determinado segmento, são oferecidas melhores condições para que seja estabelecida uma classificação mais ampla dos sons da fala — por meio da análise, por exemplo, dos valores dos formantes, da duração e do vozeamento desses sons.

Dessa forma, foram realizadas inspeções visuais do comportamento acústico dos dados produzidos por uma criança com a coleta de valo- 
res de formantes que nos auxiliaram na validação de nossas análises de oitiva que foram a base das etiquetagens dos dados. Assim, a partir de parâmetros acústicos, este artigo tem por objetivo verificar, quantitativa e qualitativamente, a emergência da líquida lateral /1/ na fala de uma criança e as estratégias de reparo empregadas na direção do alvo. É importante ressaltar, não obstante, que esta pesquisa não se propõe a discutir se houve ou não a aquisição da lateral alveolar pela criança.

Assim, foram inspecionadas as produções da palavra estrela transcrita fonologicamente como /eS'trela/ _ , realizadas pelo sujeito investigado durante o período de 1:9 (um ano e nove meses) e 2:4 (dois anos e quatro meses). Selecionou-se a palavra estrela para análise porque se obteve alto índice de produção desse vocábulo em variados estágios do processo aquisicional da criança. Além disso, registre-se que a análise ficou restrita a somente uma palavra para que se pudesse garantir o mesmo contexto linguístico para o segmento-alvo.

Por fim, vale observar que este estudo faz uma análise acústica de parte dos dados que foram coletados para uma pesquisa de mestrado (MARQUES, 2016), que, à luz do Modelo Padrão de Aquisição de Contrastes (PAC), proposto por Lazzarotto-Volcão (2009), analisou a aquisição de contrastes entre consoantes de duas crianças, falantes monolíngues do PB, no período de 1:2 a 2:6.

Assim, para apresentar a pesquisa aqui proposta, o artigo traz, na próxima seção, algumas das características acústico-articulatórias que definem a lateral alveolar. Na sequência, são apresentados estudos sobre a aquisição de /1/ e as estratégias de reparo mais comumente empregadas por crianças brasileiras no período de aquisição. Ato contínuo, foi feita uma breve discussão sobre contrastes encobertos. Prosseguindo, foram apresentados a metodologia e os resultados obtidos por meio da análise dos dados, qualitativa e quantitativa, finalizando-se com as considerações finais.

\section{Características acústicas da lateral /1/}

As consoantes líquidas laterais são produzidas a partir do bloqueio da passagem da corrente de ar. Quando essa obstrução é feita pela ponta da língua em direção aos alvéolos, permitindo um escape lateral, tem-se a lateral alveolar /1/ (MEZZOMO; RIBAS, 2004). Segundo Silva (1996), a lateral alveolar pode ser identificada através da continuidade espectral, pela trajetória de formantes bem definida e pela forma de onda regular. Essas características podem ser observadas na Figura 1. 
Figura 1 - (a) Forma de onda e (b) espectrograma de banda larga da lateral em posição de ataque medial na palavra elas. Valores médios de frequências de F1 $(437 \mathrm{~Hz}), \mathrm{F} 2(1198 \mathrm{~Hz})$ e F3 $(2600 \mathrm{~Hz})$.

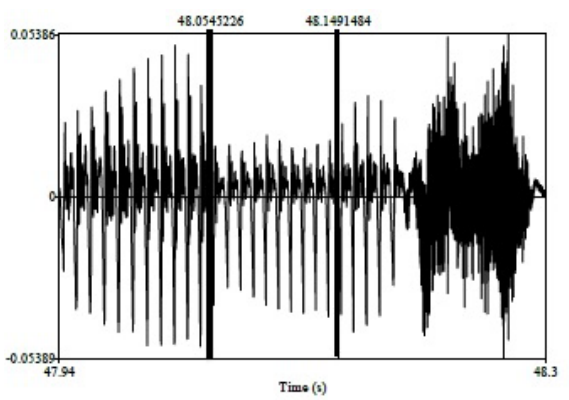

(a)

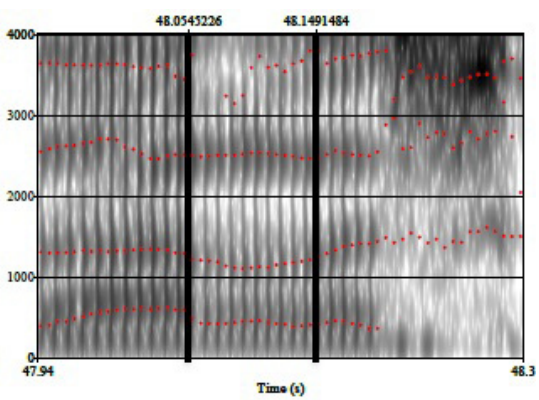

(b)

Fonte: BROD (2014, p. 36).

Na Figura 1, é possível observar que a lateral (no centro da figura, entre linhas pretas) exibe forma de onda (em (a)) e formantes contínuos (em (b)). Tais propriedades evidenciam o quanto a lateral alveolar se assemelha às vogais e justificam a dificuldade de identificar e segmentar esse som, principalmente quando os segmentos vizinhos são vocálicos. Percebe-se, contudo, que há uma redução de energia na lateral, observada na forma de onda da Figura 1 (a), quando comparada às vogais adjacentes. Por conta da semelhança das laterais com as vogais, uma análise espectral da lateral, assim como das demais líquidas, deve ser realizada com muita prudência e critério.

No que diz respeito aos valores dos formantes, sabe-se que as frequências do primeiro formante (F1) estão relacionadas com a altura da língua, enquanto as frequências do segundo formante (F2) oferecem, de modo geral, informação acerca do avanço/recuo da língua. Ademais, os valores de F1 e F2 constituem medidas importantes para a caracterização das líquidas, das nasais e das vogais, por exemplo.

Ainda em relação aos formantes, Lindbloom e Sundberg (1971) mostram que há um crescimento no valor de F2 para as consoantes que são produzidas com a língua retraída em direção ao palato mole, que é o caso da palatal $[K]$ e, dessa forma, haveria uma maior distância entre F1 e F2 para a consoante palatal. Entretanto, como os valores de F2 são mais baixos na produção da lateral alveolar, uma vez que a língua é menos retraída, haveria uma menor distância entre F1 e F2 para a lateral alveolar. 
Brod (2014), pesquisando as laterais, a partir de dados da variedade dialetal florianopolitana, apresenta valores médios de frequência $(\mathrm{Hz})$ das laterais alveolares, bem como a diferença de F2-F1. Esses valores estão exibidos na Tabela 1.

Tabela 1 - Médias de F1 e F2 da lateral alveolar produzida por falantes florianopolitanos.

\begin{tabular}{|c|c|c|}
\hline F1 (Hz) & F2 (Hz) & F2-F1 (Hz) \\
\hline 361 & 1482 & 1122 \\
\hline
\end{tabular}

Fonte: BROD (2014, p. 123).

Pagan-Neves (2008), por sua vez, trabalhando com consoantes líquidas, descreveu e comparou as produções de um grupo de sujeitos com transtorno fonológico a um grupo de sujeitos sem alterações de fala. Para o último grupo, constituído por cinco meninas e cinco meninos, com idades compreendidas entre 5:11 e 9:2, a autora coletou os valores médios de frequência $(\mathrm{Hz})$ das laterais alveolares. Esses valores são apresentados na Tabela 2.

Tabela 2 - Médias de F1 e F2 da lateral alveolar produzida por crianças (entre 5:11 e 9:2) sem alterações de fala.

\begin{tabular}{|c|c|c|c|}
\cline { 2 - 4 } \multicolumn{1}{c|}{} & F1 (Hz) & F2 (Hz) & F2-F1 (Hz) \\
\hline Masculino & 390,1 & 1398,5 & 1008,4 \\
\hline Feminino & 421,8 & 1485,5 & 1063,7 \\
\hline
\end{tabular}

Fonte: PAGAN-NEVES (2008, p. 187).

Com base nos dados de Brod (2014) e Pagan-Neves (2008), notou-se que as diferenças resultantes de F2-F1 são bastante semelhantes, ficando em torno de $1000 \mathrm{~Hz}$. Esses valores servirão de base para a análise dos dados deste trabalho. 
Assim, com base nos comportamentos acústicos anteriormente apresentados, foi inspecionada, neste estudo, a diferença entre F2-F1, a fim de caracterizar as laterais exibidas nas produções da criança a partir de seus graus de posteriorização. Ainda foram utilizadas medidas de F1 e F2 para observar as substituições por vogais e até mesmo ratificar omissões percebidas de oitiva. É interessante relembrar que os dados foram inicialmente etiquetados de oitiva. E, por essa razão, toda a investigação acústica aqui exposta (seja por inspeção visual, de cunho mais qualitativo, ou com base nos valores de formantes, de cunho mais quantitativo) será usada também para a validação e correção (se necessário) das etiquetagens realizadas de oitiva. Esse procedimento, consequentemente, permitirá também verificar se há gradiência nas produções de /1/ realizadas pelo infante.

Sabe-se ainda que a inspeção visual da trajetória dos formantes é uma maneira de estudar vogais, pois sons vocálicos são caracterizados por suas duas primeiras frequências de ressonância. As vogais altas que são articuladas com um levantamento do corpo da língua, criando uma constrição estreita que gera baixas frequências (STEVENS, 2000), apresentam valores mais baixos de F1. O contrário disso ocorre para a vogal [a], que é produzida com a língua numa posição mais baixa e, por isso, apresenta valores mais altos para F1.

Com relação ao avanço/recuo da língua, sons produzidos com a posição de língua mais avançada apresentam valores altos de F2, como ocorre com as vogais anteriores. No entanto, sons produzidos com a língua em uma posição mais recuada apresentam valores de F2 mais baixos, como ocorre com as vogais posteriores. Já as vogais médias, de acordo com a posição de altura e avanço/recuo da língua, possuem suas frequências distribuídas entre os valores das vogais altas e baixas, como pode ser observado na Figura 2, que apresenta as médias obtidas para vogais do PB, com base em Brod e Seara (2013). 
Figura 2 - Formantes vocálicos relacionados à altura (F1) e ao avanço-recuo da língua (F2)

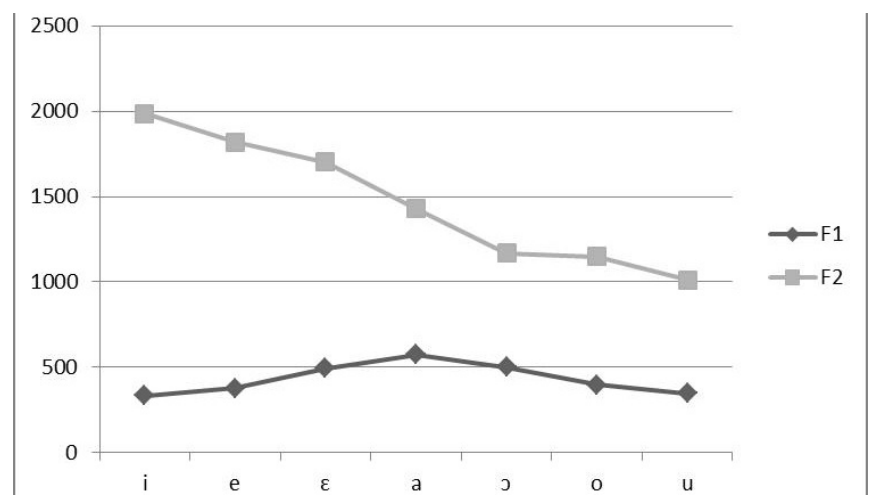

Fonte: Próprio autor - com base nos dados de Brod e Seara (2013, p. 120).

Sabe-se também que os sons vocálicos são caracterizados por serem emitidos sem obstrução da corrente de ar. Ao contrário do que acontece na produção dos sons consonantais, na produção das vogais não há fricção do ar e o canal articulatório é relativamente amplo. A consequência desses eventos é a de que segmentos vocálicos apresentam maior intensidade (energia) quando comparados a segmentos consonantais. Essas informações foram utilizadas na caracterização acústica qualitativa das variantes encontradas (se consonantais ou vocálicas) nas produções do sujeito da pesquisa.

A seguir, são apresentadas algumas pesquisas que investigaram o processo de aquisição da líquida lateral alveolar, assim como as estratégias de reparo mais comumente utilizadas para esse segmento.

3 Estudos sobre a aquisição da lateral /1/ e as estratégias de reparo

Das líquidas, a lateral /1/ é a primeira a ser adquirida pelas crianças brasileiras, sendo que sua aquisição é mais estável e inicial do que a do $/ K /$. Além disso, considera-se o /1/ a consoante prototípica da classe das líquidas, pois é comumente produzida, durante o processo de aquisição fonológica, no espaço de qualquer outro fonema dessa classe, em todas as posições da sílaba e da palavra (LAMPRECHT et al., 2004).

Matzenauer-Hernandorena e Lamprecht (1997) analisaram os dados de fala de 310 crianças entre 2:0 e 7:1 e verificaram que a líquida 
lateral /1/ é adquirida em posição de onset absoluto, aos 2:8, e dominada pouco depois, aos 3:0, em onset medial. Em relação aos ambientes fonológicos favorecedores à aquisição do $/ 1 /$, essas autoras afirmam que são favoráveis as vogais [a] e [ع], no contexto precedente, e as vogais [a], [i] $\mathrm{e}[\mathrm{u}]$, no contexto seguinte.

Em relação à tonicidade da sílaba, Azambuja (1998) e Bonini (2012) verificaram que o /1/ em sílaba postônica é mais preservado, isto é, há menor incidência de estratégias de reparo empregadas. Entretanto, Henandorena e Lamprecht (1997) consideram a sílaba tônica a mais favorecedora para a aquisição do /1/, concordando com a literatura geral que indica ser a sílaba tônica a mais facilitadora à aquisição dos fonemas (MATZENAUER-HERNANDORENA, 1990).

Azambuja (1998) observou que o processo de domínio desse fonema não é linear, pois apresenta quedas de produção, ou seja, regresso no emprego de /1/ entre as idades de 2:6 e 2:8 e 2:10 e 3:0. Esse regresso observado não é visto exclusivamente na aquisição do segmento em discussão, mas parece ser uma característica do processo de aquisição.

Lazzarotto-Volcão (2009) propôs o Modelo Padrão de Aquisição de Contrastes (PAC), em que são estabelecidas quatro etapas de aquisição fonológica. Segundo a autora, é na terceira etapa de aquisição, entre 2:8 e 3:0, aproximadamente, que /1/ emerge na gramática da criança, sendo a coocorrência dos traços [+aproximante, -contínuo, coronal, +anterior] responsável pelo surgimento do segmento.

Em relação às estratégias de reparo, Matzenauer-Hernandorena (1990) aponta duas delas empregadas para o alvo /1/: a sua não realização e o emprego do glide em seu lugar. Sobre a não realização fonética de /1/ na posição de onset absoluto e na posição intervocálica, a autora verificou ocorrências na faixa etária de 1:8 a 2:3. Observou, no entanto, que há um declínio no uso dessa estratégia à medida que a idade das crianças aumenta.

Os dados de Matzenauer-Hernandorena (1990) mostram que o uso das semivogais [j] e [w] em lugar da lateral ocorre quando esta é antecedida ou precedida por vogal [+arredondada]. A autora constatou essa estratégia em poucos sujeitos estudados, concluindo que esse é um processo bastante fraco na aquisição do português.

De forma similar, Azambuja (1998 apud MEZZOMO \& RIBAS, 2004) constatou que, entre as idades de 2:0 e 4:0, as estratégias de reparo mais utilizadas no processo de domínio de /1/ pelas crianças são: apagamento do segmento e da sílaba (por exemplo: "estrelinha" $\rightarrow$ [ite'ije]); 
"televisão" $\rightarrow$ [tevi'z̃̃]); a semivocalização com os glides [j] e [w] (por exemplo: "bala" $\rightarrow$ ['bawe]; "cabelo" $\rightarrow$ [ka'beju]); e a realização de $[\mathrm{n}]$ ou [r] no lugar de /1/ (por exemplo: "lápis" $\rightarrow$ ['napis]; "calo" $\rightarrow$ ['karu]). A autora salienta, no entanto, que a produção de /1/ como [ $\mathrm{r}$ ] é pouco esperada devido à aquisição posterior de / $\mathrm{R} /$ em relação a /1/. Além dessas, outras estratégias foram usadas pelas crianças, tais como: emprego de plosivas (por exemplo: "bola" $\rightarrow[$ 'go.ke]) e de nasais (por exemplo: "bala" $\rightarrow$ ['ã.me]).

Por fim, é importante frisar que, embora a ordem de aquisição e as estratégias de reparo citadas sejam consideradas o padrão para o português brasileiro, não se descarta a existência de variações individuais. Portanto, dentro das etapas e características gerais do desenvolvimento fonológico (aquelas que podem ser encontradas em todas as crianças), existe possibilidade de oscilação individual quanto ao domínio segmental e prosódico. Nesse sentido, conforme Lamprecht et al. (2004), a variação dá-se tanto em relação à idade de aquisição quanto aos caminhos percorridos para atingir a produção adequada.

Por outro lado, estudos que investigaram os fenômenos da fala infantil, por meio de análise acústica, revelaram que é possível haver produções intermediárias entre as variantes resgatadas pelo ouvido do analista. Esse assunto será brevemente apresentado na próxima seção.

\section{Estudos sobre contrastes encobertos}

Pesquisas na área de aquisição fonológica têm evidenciado por meio de análise acústica e/ou articulatória que há — nos momentos iniciais da aquisição da linguagem e também em produções de crianças com desvios fonológicos — produções intermediárias no processo de aquisição de um determinado contraste fônico que são caraterizadas pela presença de contrastes encobertos.

Neste processo, podem ser verificadas produções intermediárias e gradientes que se assemelham ao padrão adulto, porém não são identificadas como tais. Esses contrastes são definidos como contrastes fônicos imperceptíveis auditivamente, mas detectáveis acústica e/ou articulatoriamente. Segundo Oliveira (2010, p. 11), contraste encoberto “é um fenômeno descrito na literatura como um processo intermediário entre a neutralização fônica e a produção efetiva de contraste". Para o autor, isso ocorre quando o falante está "produzindo uma diferença sistemática para duas categorias fonológicas diferentes, mas esta diferença (contraste) não 
é o 'padrão' para aquela língua, passando despercebida por seus falantes" (idem).

Silva (2002), ao pesquisar a alofonia dos róticos iniciais no $\mathrm{PB}$, lembra que algumas alofonias tradicionalmente tidas como categóricas são, na verdade, gradientes. Ao estudar acusticamente os róticos, a autora não só verificou a existência de categorias intermediárias, mas também observou um contínuo físico entre elas. "Nesse sentido, a alofonia dos róticos iniciais em PB mostrou-se gradiente, e não categórica, como podem fazer pensar estudos fonológicos baseados numa investigação impressionística." (SILVA, 2002, p. 22).

De acordo com Berti (2010), boa parte das substituições fônicas julgadas auditivamente na aquisição da fala com e sem desvios são, na realidade, contrastes fônicos encobertos. Com base nisso, a autora investigou acusticamente as substituições para o contraste fônico entre /t/ e $/ k$ / na fala de crianças em aquisição típica e com desvio. Analisando os dados, constatou $80 \%$ de presença de contrastes encobertos na fala das crianças com transtorno fonológico e 57,4\% nas crianças em fase de aquisição típica da fala. Isso quer dizer que boa parte dos dados que poderiam ser considerados como não apresentando os contrastes necessários, já evidenciavam algum detalhe que identificava características acústicas relacionadas aos sons-alvo em aquisição. As análises de oitiva não permitiam tal detalhamento.

Além de Silva (2002) e Berti (2010), outros estudos constataram a presença de contrastes encobertos no processo de aquisição, sendo oportuno destacar, como referências, as pesquisas de Berti (2006), Vaz (2010), Cristofolini (2013) e Cemin (2014).

\section{Metodologia}

O presente trabalho apresenta-se como uma pesquisa híbrida do ponto de vista metodológico, na medida em que são utilizados tanto o método qualitativo, a partir de inspeções visuais dos dados acústicos, quanto o quantitativo, com base em parâmetros acústicos, como os formantes. Caracteriza-se, também, como uma pesquisa longitudinal e de caráter exploratório, que visa, com a gravação de dados de uma criança em aquisição, a averiguar as variantes que substituem a lateral alveolar. Esta pesquisa foi certificada pelo Comitê de Ética da UFSC, sob o número 2057.

Os dados deste estudo são de um menino, falante monolíngue do português brasileiro, apresentando, até então, desenvolvimento físico, 
psicológico e fonético-fonológico considerados normais.

Como foi mencionado na introdução, esta pesquisa corresponde a um recorte do corpus utilizado em Marques (2016). Esse conjunto de dados é composto por 34 produções do vocábulo estrela. Foi escolhida apenas essa palavra a fim de garantir o mesmo contexto para a lateral /1/, bem como porque foi percebido um alto índice de produção dessa palavra pela criança.

As coletas foram realizadas mensalmente, em ambiente natural, durante o período compreendido entre 1:9 e 2:4 de idade. A escolha dessa faixa etária ocorreu em virtude de que o início do processo de aquisição é caracterizado por um alto índice de estratégias de reparo pelas crianças. As produções foram registradas em áudio e vídeo, porém, para a análise acústica, foram analisados apenas os dados relativos ao áudio. Esse áudio era em formato $m p 3$ e foi convertido para wav pelo software de análise de fala Ocenaudio $^{1}$ (versão 2.015). Apesar dessa conversão e de a coleta não ter sido gravada em cabine acústica, os dados são bastante adequados para as análises acústicas e não foi necessária a eliminação de ruídos, dada a sua qualidade sonora. A taxa de amostragem foi de $48 \mathrm{kHz}$.

\subsection{Etiquetagens de dados}

A etiquetagem dos dados foi feita com o auxílio do software Praat v. 5.2.15 (BOERSMA; WEENINK, 2017), por meio do recurso TextGrid, que permite a segmentação e etiquetagem, em diferentes camadas, de fones, sílabas ou palavras.

Para este estudo, foram geradas três camadas: a primeira, intitulada de "Lateral", apresenta a etiquetagem da região correspondente à produção da lateral alveolar ou de suas variantes, acrescida das regiões de coarticulação à direita e à esquerda do alvo. A segunda camada, intitulada "Contexto", apresenta a etiquetagem da região que corresponde à produção de [1] ou de suas variantes, acrescida dos sons vocálicos circunvizinhos. A terceira camada, intitulada "Palavra", apresenta a região equivalente à produção da palavra-alvo /es'trela/. Na Figura 3, tem-se um exemplo das etiquetagens realizadas. 
Figura 3 - Exemplo de etiquetagem, com auxílio do software Praat, da variável ['tele] produzida pela criança com 1:11.

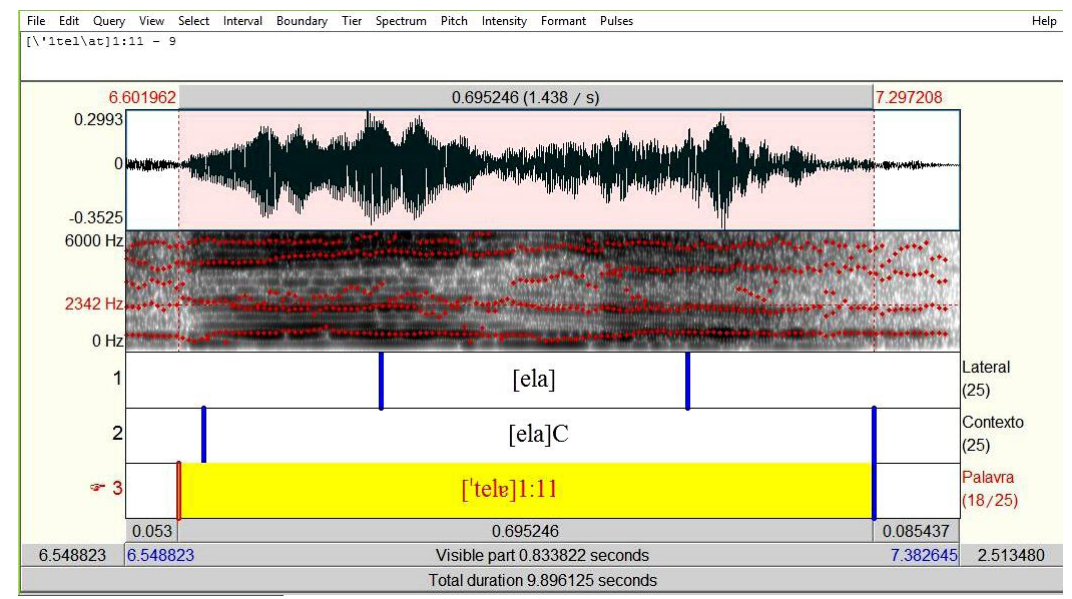

Fonte: próprio autor.

Inicialmente, com uma análise de oitiva foram detectadas as diferentes produções para a palavra-alvo. Em seguida, a fim de observar se o critério, empregado na etiquetagem dos dados da camada intitulada Lateral, estaria de acordo com o que prediz a literatura, foi feita uma análise qualitativa. Dessa forma, por meio de uma inspeção visual, foi avaliada, nas variantes transcritas, a energia apresentada nos espectrogramas. Assim, para identificar consoantes, foram observadas regiões com menor intensidade, consequência da obstrução que ocorre nesses segmentos. E, para identificar vogais, foram observadas regiões de maior intensidade, uma vez que tais segmentos são produzidos sem obstruções. Ainda pela inspeção visual, foi observada a trajetória dos formantes. Na sequência, foi realizada uma análise quantitativa, coletando os valores dos dois primeiros formantes que auxiliariam na caracterização das variantes encontradas. A partir das análises acústicas, foram validadas as etiquetagens e feitas re-etiquetagens, quando necessário.

Para a coleta dos valores dos formantes, foi feita a extração automática de F1 e F2 utilizando um script ${ }^{2}$ - ferramenta que realiza automaticamente uma sequência de operações programadas —, elaborado com o intuito de gerar tabelas com valores de frequência formântica em um ponto de um arquivo de som selecionado manualmente. O script foi roda- 
do na camada onde se encontrava a produção do som-alvo, denominada Lateral (Figura 3).

Feito isso, as medidas de F1 e F2 foram coletadas em cinco pontos equidistantes da produção-alvo, que foram determinados no script em relação às regiões de: início (ponto 1 ), meio (pontos 2,3 e 4 ) e fim do segmento (ponto 5). Com intuito de apurar as medidas dos formantes relativos ao segmento-alvo, selecionaram-se os valores de F1 e F2 apresentados no ponto 3 , uma vez que este ponto, juntamente com os pontos $2 \mathrm{e}$ 4, se encontram na região medial do segmento que, em geral, é a região mais estável para a coleta de dados acústicos ${ }^{3}$.

\section{Análise dos dados}

Depois de selecionadas as 34 produções relacionadas à palavra estrela, foi verificado que as estratégias de reparo utilizadas pela criança foram: (i) a omissão da lateral e a consequente produção de ['tee] ; (ii) a semivocalização, produzindo ['teje]; (iii) a palatalização da lateral ['te $K$ e]; (iv) uma produção com ditongação e produção do alvo /l/ ['tejle]; e (v) a produção da lateral como a do alvo-adulto ['tele].

Na Tabela 3, a seguir, são mostradas as produções do sujeito a cada sessão de gravação ao longo do estudo.

Tabela 3 - Variantes observadas para a palavra estrela entre 1:9 e 2:4

\begin{tabular}{|c|c|}
\hline Idade & Variantes \\
\hline $1: 9$ & {$\left[{ }^{\text {teje }}\right][$ lee $]$} \\
\hline $1: 10$ & ['tele] \\
\hline $1: 11$ & {$\left[{ }^{\text {tele }}\right]\left[{ }^{\text {te }} \hat{\mathrm{C}} \mathrm{e}\right]$} \\
\hline $2: 0$ & {$\left[{ }^{1}\right.$ tejle $][$ 'te $\hat{\prime} \mathrm{e}]$} \\
\hline $2: 1$ & {$\left[{ }^{\text {teje }}\right]$} \\
\hline $2: 2$ & {$\left[{ }^{\text {tee }}\right]\left[{ }^{1}\right.$ teje $]\left[{ }^{1}\right.$ tele $]$} \\
\hline $2: 3$ & {$\left[{ }^{1}\right.$ teje $]\left[{ }^{1}\right.$ tejle $]\left[{ }^{1}\right.$ tele $]\left[{ }^{1}\right.$ te $\left.K \mathfrak{l}\right]$} \\
\hline $2: 4$ & ['tele] \\
\hline
\end{tabular}

Fonte: Próprio autor. 
Cada uma dessas variantes foi primeiramente analisada qualitativamente, com base na trajetória dos formantes e na observação da intensidade na região dos sons-alvo exibidas nos espectrogramas, e na sequência foi analisada quantitativamente.

\subsection{Análise qualitativa}

Iniciou-se a análise qualitativa pelos dados que foram caracterizados pela omissão do som-alvo. Assim, com base nos movimentos dos dois primeiros formantes vocálicos, mostrados no gráfico da Figura 2, e na trajetória desses formantes, exibida, a seguir, no espectrograma da Figura 4, percebe-se a passagem da vogal média-alta [e] para a vogal baixa central [e], caracterizada pelo aumento de $\mathrm{F} 1$ e diminuição de F2. Essas observações ratificam a análise de oitiva que indicou a omissão da lateral.

Figura 4 - Espectrograma de [ê] na variante ['tee ], produzida pela criança com 1:9.

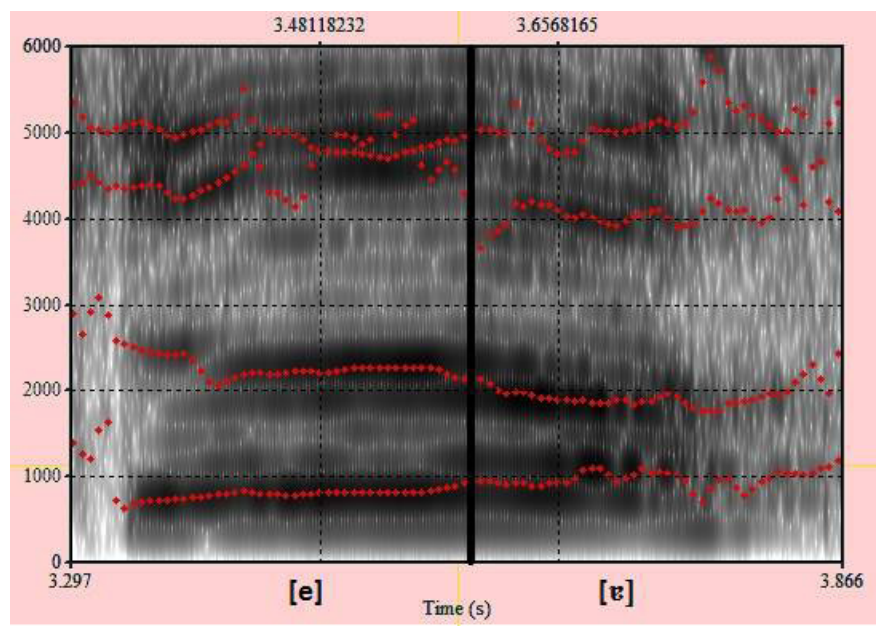

Fonte: próprio autor.

Na sequência, foram avaliados os dados que caracterizavam a semivocalização. Desse modo, com base na trajetória dos dois primeiros formantes que exibem uma pequena mudança nos seus valores, como pode ser visto na Figura 5, fica evidenciada a passagem de [e] para [j] a partir de uma pequena queda de F1 e um aumento de F2. Ou seja, um 
movimento de $\mathrm{F} 1$ para valores mais baixos (próprios de vogais altas) e um movimento de $\mathrm{F} 2$ para valores mais altos (próprios de vogais anteriores), demonstrando a presença da semivogal anterior alta que tem posição mais anteriorizada do que a vogal média-alta anterior. A partir da produção de [j], nota-se uma trajetória realçada por um movimento de F1 para valores mais altos e de F2 para valores mais baixos, caracterizando a passagem de [j] para [e]. Novamente, essas considerações ratificam as análises de oitiva realizadas que indicou a presença da semivocalização em substituição à lateral alveolar.

Figura 5 - Espectrograma da variante ['eje], produzida pela criança com 1:9.

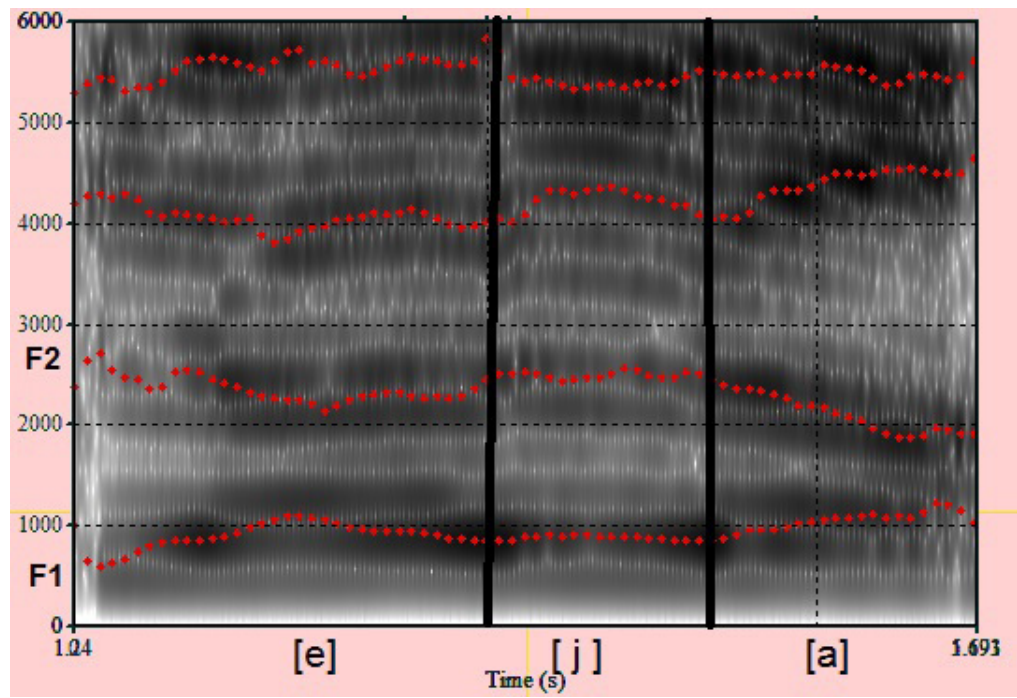

Fonte: próprio autor.

Pode-se dizer, nesse contexto, que as produções de ['e1 $\mathrm{k}]$ e ['eje], exemplificadas nas Figuras 4 e 5, apresentam trajetórias de formantes de acordo com a sequência apresentada anteriormente na Figura 2 (Seção 2). Ainda considerando a intensidade de sons vocálicos, era esperado que, tanto na produção de ['ee] quanto na de ['eje], os espectrogramas apresentassem muita intensidade, já que não houve nenhuma obstrução da corrente de ar. Esse fato foi confirmado pela energia exibida (escurecimento do sinal) nos dados expostos nas Figuras 4 e 5. 
Em relação às demais variantes, observa-se que, durante as produções de ['eǨ] e ['ejle], conforme Figuras 6 e 7, respectivamente, há uma considerável diminuição de energia no momento da produção dos sons consonantais, se comparados às das vogais circunvizinhas. Nota-se, também, que, em ['eKe], antecedendo a consoante, ocorreu um maior afastamento entre F1 e F2, caracterizando a produção da vogal [e] e, seguindo a consoante, há a aproximação das trajetórias de F1 e F2, que caracterizam a vogal [e]. Na produção de ['ejle], a seu turno, constatou-se um distanciamento mediano entre os valores de F1 e F2 para a vogal [e], seguido de um maior afastamento entre os valores dos formantes para [j], sons vocálicos que antecedem a consoante.

Figura 6 - Exemplo produção de ['eאe], produzida pela criança com 2:3.

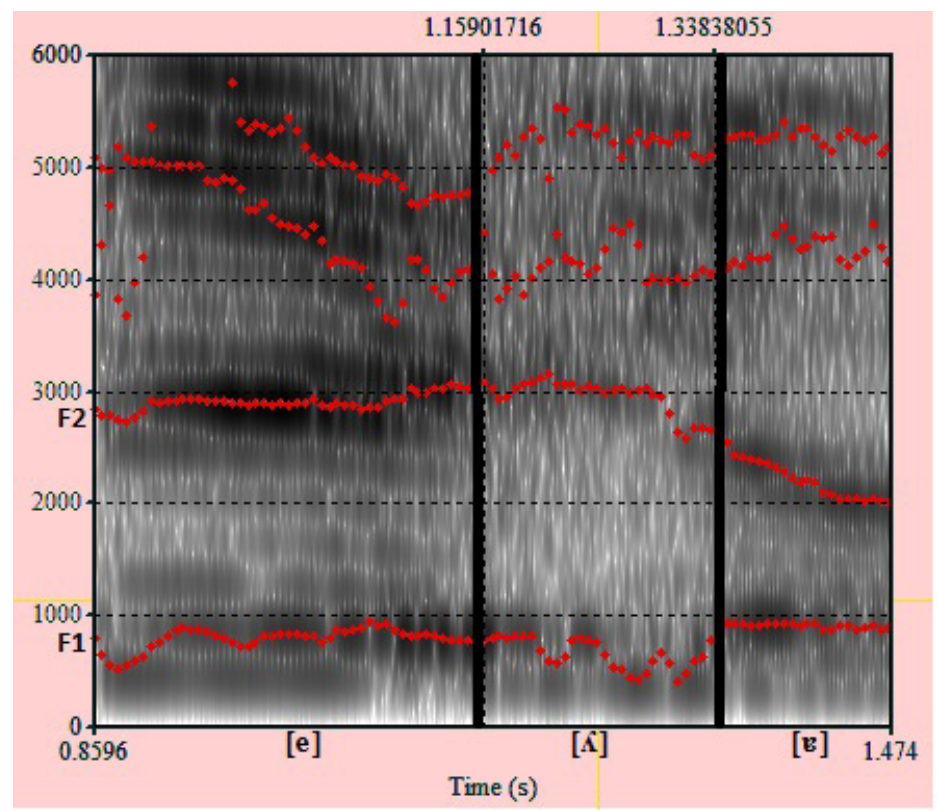

Fonte: próprio autor.

Como já observado em relação aos formantes, estudos têm mostrado que há um crescimento no valor de F2 para as consoantes que são produzidas com a língua retraída em direção ao palato mole, como é o caso da palatal [K] (LINDBLOOM e SUNDBERG, 1971). Assim, a maior 
distância entre F1 e F2, observada no espectrograma da consoante palatal na Figura 6, é um dos aspectos que permite distinguir as duas laterais. Observe, na Figura 7, que os valores de F2 são descendentes na produção da lateral alveolar. E ainda, nessa figura, nota-se um clareamento na intensidade exibida na região que indica a presença da lateral, se comparada às vogais circunvizinhas.

Figura 7 - Espectrograma da variante ['ejle], produzida pela criança com 2:3.

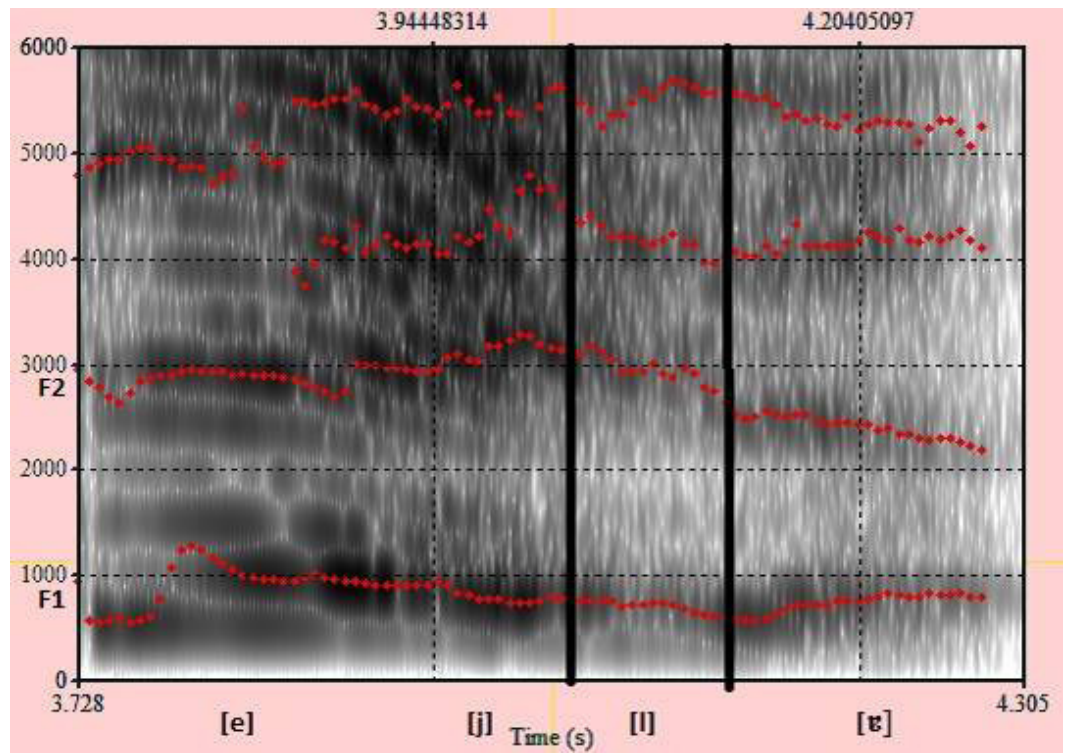

Fonte: próprio autor.

Na Figura 8, é apresentado um exemplo da produção da variante ['ele]. Nessa figura, no momento da produção da lateral, há uma considerável queda de energia e, em seguida, um estreitamento entre os valores dos formantes para a vogal $[\mathrm{e}]$. 
Figura 8 - Espectrograma da variante ['ele], produzida pela criança com 2:4.

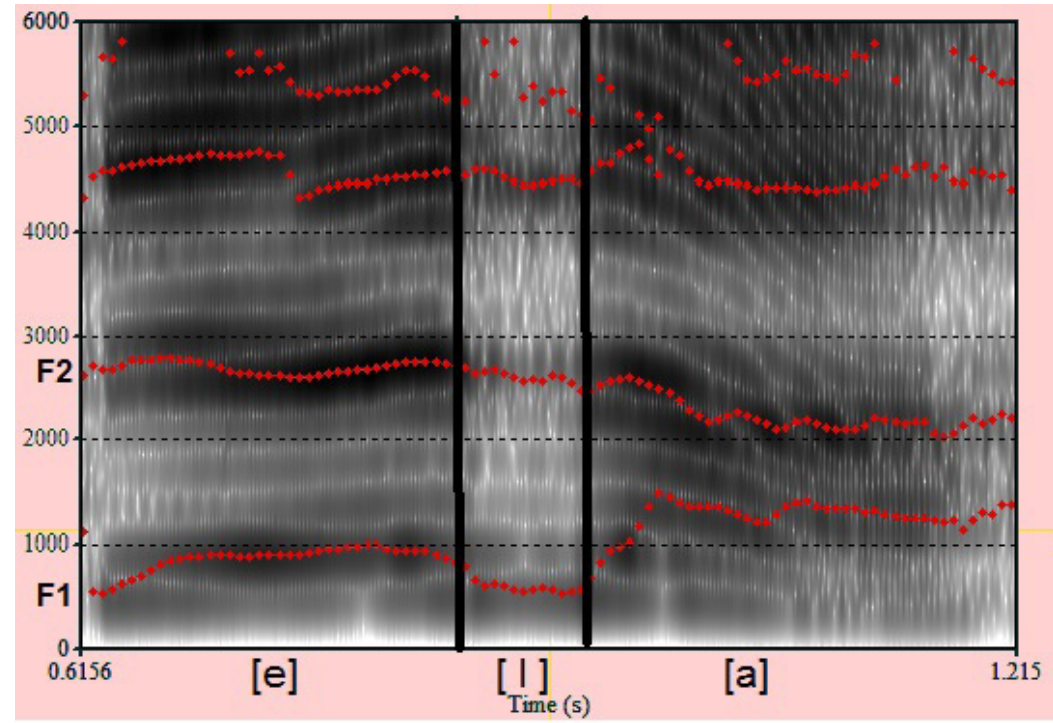

Fonte: próprio autor.

\subsection{Análise quantitativa}

Feita a análise qualitativa dos dados, seguiu-se para a análise quantitativa, buscando identificar as características distintas das variantes encontradas. Para isso, foram analisados os valores das frequências dos formantes e, sobretudo, a diferença entre F2-F1, conforme ressaltaram os estudos anteriormente descritos (LINDBLOOM; SUNDBERG, 1971 e BROD, 2014). Vale consignar, nesse aspecto, que não foram considerados os valores resultantes de F3-F2, pois, de acordo com o estudo de Brod (2014), a diferença entre esses dois formantes não é significativa para a descrição acústica das laterais.

Os dados referentes às variantes produzidas foram coletados a partir dos procedimentos explicitados na metodologia. Na Tabela 4, são exibidos os valores dos dois primeiros formantes dos sons percebidos como lateral ou como glide, coletados de cada variante apresentada nas diversas sessões de gravação realizadas. A partir desses valores, foi calculada a diferença de F2-F1. Nessa tabela, as variantes indicadas basearam-se nas análises de oitiva (quando da etiquetagem dos dados) e qualitativa, apresentada anteriormente (Seção 6.1). 
Tabela 4 - Valores de F1, F2 e F2-F1 coletados em cada uma das variantes produzidas pela criança em função da idade em cada sessão de gravação ${ }^{4}$

\begin{tabular}{|c|c|c|c|c|c|c|c|c|c|c|c|c|}
\hline \multirow[b]{2}{*}{$\begin{array}{l}\text { Ida- } \\
\text { de }\end{array}$} & \multicolumn{3}{|c|}{ [1] - variante ['tele] } & \multicolumn{3}{|c|}{ [j] - variante ['teje] } & \multicolumn{3}{|c|}{ [1] - variante ['tejle] } & \multicolumn{3}{|c|}{$\begin{array}{l}{[K]-\text { variante }} \\
{[\text { 'te } K \mathrm{r}]}\end{array}$} \\
\hline & F1 & F2 & $\begin{array}{l}\text { F2- } \\
\text { F1 }\end{array}$ & $\mathrm{F} 1$ & F2 & $\begin{array}{l}\text { F2- } \\
\text { F1 }\end{array}$ & F1 & F2 & F2-F1 & F1 & $\mathrm{F} 2$ & $\begin{array}{l}\text { F2- } \\
\text { F1 }\end{array}$ \\
\hline \multirow[t]{3}{*}{ 1:09 } & - & - & - & 713 & 2423 & 1709 & - & - & - & - & - & - \\
\hline & - & - & - & 735 & 2713 & 1979 & - & - & - & - & - & - \\
\hline & - & - & - & 716 & 2756 & 2039 & - & - & - & - & - & - \\
\hline \multirow[t]{5}{*}{$1: 10$} & 763 & 2395 & 1632 & - & - & - & - & - & - & - & - & - \\
\hline & 809 & 1882 & 1073 & - & - & - & - & - & - & - & - & - \\
\hline & 736 & 2404 & 1668 & - & - & - & - & - & - & - & - & - \\
\hline & 970 & 2701 & 1730 & - & - & - & - & - & - & - & - & - \\
\hline & 694 & 2673 & 1815 & - & - & - & - & - & - & - & - & - \\
\hline \multirow[t]{7}{*}{$1: 11$} & 988 & 2673 & 1685 & - & - & - & - & - & - & 662 & 2829 & 2167 \\
\hline & 877 & 2610 & 1733 & - & - & - & - & - & - & - & - & - \\
\hline & 741 & 2485 & 1744 & - & - & - & - & - & - & - & - & - \\
\hline & 738 & 1972 & 1234 & - & - & - & - & - & - & - & - & - \\
\hline & 1029 & 1873 & 844 & - & - & - & - & - & - & - & - & - \\
\hline & 877 & 2324 & 1446 & - & - & - & - & - & - & - & - & - \\
\hline & 765 & 2216 & 1451 & - & - & - & - & - & - & - & - & - \\
\hline $2: 00$ & - & - & - & - & - & - & 705 & 2917 & 2212 & 785 & 2946 & 2191 \\
\hline 2:01 & - & - & - & 620 & 2860 & 2240 & - & - & - & - & - & - \\
\hline \multirow[t]{4}{*}{$2: 02$} & 855 & 2372 & 1517 & 823 & 2778 & 1955 & - & - & - & - & - & - \\
\hline & 903 & 2504 & 1601 & - & - & - & - & - & - & - & - & - \\
\hline & 1042 & 2293 & 1251 & - & - & - & - & - & - & - & - & - \\
\hline & 878 & 2368 & 1490 & - & - & - & - & - & - & - & - & - \\
\hline \multirow[t]{2}{*}{$2: 03$} & 917 & 2628 & 1712 & 802 & 3154 & 2352 & 832 & 2757 & 1925 & 706 & 2914 & 2208 \\
\hline & - & - & - & 787 & 2933 & 2146 & 785 & 2946 & 2160 & - & - & - \\
\hline \multirow[t]{2}{*}{ 2:04 } & 820 & 2693 & 1873 & - & - & - & - & - & - & - & - & - \\
\hline & 950 & 2718 & 1768 & - & - & - & - & - & - & - & - & - \\
\hline
\end{tabular}

Fonte: próprio autor. 
Pela Tabela 4, pode-se perceber a gradiência indicada pelos valores dos formantes dos dados coletados. A caracterização como lateral (alveolar ou palatal) ou glide, nessa tabela, foi apoiada não apenas nos valores dos dois primeiros formantes, mas também na análise qualitativa, em especial na energia presente no sinal em observação, mas também na análise qualitativa, em especial na energia presente no sinal em observação. Essa análise conjunta permitiu avaliar a energia do sinal na região em observação ${ }^{5}$ e identificar adequadamente a variante produzida. Essa estratégia foi usada principalmente quando havia diferença entre os valores de F2-F1 acima de $2000 \mathrm{~Hz}$, já que esse valor caracterizaria tanto uma lateral palatal quanto um glide anterior. O som em análise pôde então ser caracterizado como vogal quando a energia nessa região era bastante semelhante à energia dos sons vizinhos, conforme mostrado na Figura 5. Ou pôde ser caracterizado como lateral palatal, quando a energia da região em análise era menos intensa do que a energia dos sons vizinhos, conforme pode ser observado na Figura 6. Isso foi necessário uma vez que diferenças acima de $2000 \mathrm{~Hz}$ indicavam posteriorização do som e, nesse caso, a presença de uma consoante palatal.

Valores próximos de $1500 \mathrm{~Hz}$ foram considerados como lateral alveolar, pois esses dados se apresentaram com a menor posteriorização. Assim, quando eram verificadas diferenças próximas desse valor, também foi observado o escurecimento (energia) na região do som em análise para que se pudesse caracterizá-la como lateral alveolar ou glide. Desse modo, se a região-alvo apresentou energia semelhante à dos sons vizinhos foi considerada um glide e se apresentou um clareamento em relação às suas vizinhanças (anterior e posterior) foi considerada como lateral alveolar.

Para uma melhor visualização da posteriorização dos segmentos em análise, na Tabela 5, são apresentados os valores médios de F1, F2 e F2-F1 das variantes apresentadas na Tabela 4. 
Tabela 5 - Valores médios de F1, F2 e F2-F1 das variantes produzidas pela criança.

\begin{tabular}{|c|c|c|c|}
\hline Variantes & F1 (Hz) & F2 (Hz) & F2-F1 (Hz) \\
\hline$[K]$ em ['te $K$ r $]$ & 718 & 2896 & 2178 \\
\hline$[1]$ em ['telø] & 861 & 2410 & 1549 \\
\hline$[j]$ em ['tejle] & 774 & 2873 & 2099 \\
\hline$[j]$ em ['tejø] & 742 & 2802 & 2060 \\
\hline
\end{tabular}

Fonte: próprio autor.

Com os dados exibidos nas Tabelas 4 e 5 , foi verificada a aproximação do alvo - a lateral alveolar. Essa aproximação só pôde ser observada a partir de análises acústicas detalhadas. Os valores resultantes da diferença entre F2-F1 revelaram que, quando essa diferença diminui, ficando mais perto de $1500 \mathrm{~Hz}$, as produções estão se aproximando do segmento-alvo - a lateral alveolar, já que a diminuição dessa diferença indica uma menor posteriorização da lateral.

Os valores mostrados na Tabela 5 vão ao encontro do que prediz a literatura. Veja-se, na sequência, a Tabela 6, a qual demonstra os valores médios obtidos por pesquisas sobre laterais e vogais do PB em produções de adultos e de crianças com idades entre 10:00 e 10:11.

Tabela 6 - Valores médios das frequências dos formantes de [K], [i] e [1].

$\begin{array}{lllll}\text { Variante } & \text { F1 }(\mathrm{Hz}) & \text { F2 }(\mathrm{Hz}) & \text { F2-F1 }(\mathrm{Hz}) & \text { Fonte } \\ {[K]} & 293 & 2196 & 1903 & \text { Pagan-Neves (2008) } \\ {[\mathrm{i}]} & 335 & 1985 & 1650 & \text { Brod; Seara (2013) } \\ {[1]} & 361 & 1482 & 1122 & \text { Brod (2014) }\end{array}$

Fonte: Próprio autor. 
Comparando os dados, é notório que os valores das médias resultantes de F2-F1 da Tabela 6 são consideravelmente menores do que os apresentados na Tabela 5. Supõe-se que tal discrepância seja resultado da diferença de idade entre as crianças analisadas, já que vozes mais agudas, como as das crianças menores, apresentam frequência fundamental mais alta e, por consequência, valores de ressonâncias mais altos também.

Segundo Vanzella (2006, p. 10), a frequência fundamental começa «inicialmente bastante aguda nos bebês recém-nascidos $(440 \mathrm{~Hz})$, vai lentamente decrescendo e, aos 3 anos de idade, situa-se ao redor de $230 \mathrm{~Hz}$, até a pré-adolescência, quando encontramos os valores médios em torno de 290Hz." Além disso, as sessões de coleta de fala deste estudo envolveram atividades lúdicas que deixaram a criança um pouco agitada. De acordo com Braga, Oliveira e Sampaio (2009, p. 124), "atividades lúdicas e desportivas bastante energéticas que geram hipertensão cervical provocam, como consequência, contração muscular excessiva dos músculos da fonação. Esta contração influencia a qualidade vocal caracterizando a voz com um pitch mais agudo."

As situações justificadas acima, somadas ao fato de não haver, na literatura atual, parâmetros referentes a F1 e F2 para crianças tão pequenas, nos levam a considerar os dados apresentados na Tabela 5 pertinentes aos propósitos deste estudo.

Dessa forma, os resultados exibidos nas Tabelas 5 e 6 seguem o que prediz a literatura, ou seja, há um crescimento no valor de F2 da lateral alveolar para a lateral palatal, assim como há uma maior distância entre F1 e F2 para a consoante palatal. Observe-se, na Figura 9, um resumo comparativo, com base nas Tabelas 5 e 6 , do comportamento das médias de F2-F1.

Com a Figura 9, depreende-se que os valores da diferença entre F2-F1 vão decrescendo da lateral palatal, passando pelos sons vocálicos altos anteriores até a lateral alveolar que apresenta o menor valor. Esse comportamento ratifica, portanto, as variantes encontradas. 


\section{Valores de F2-F1}

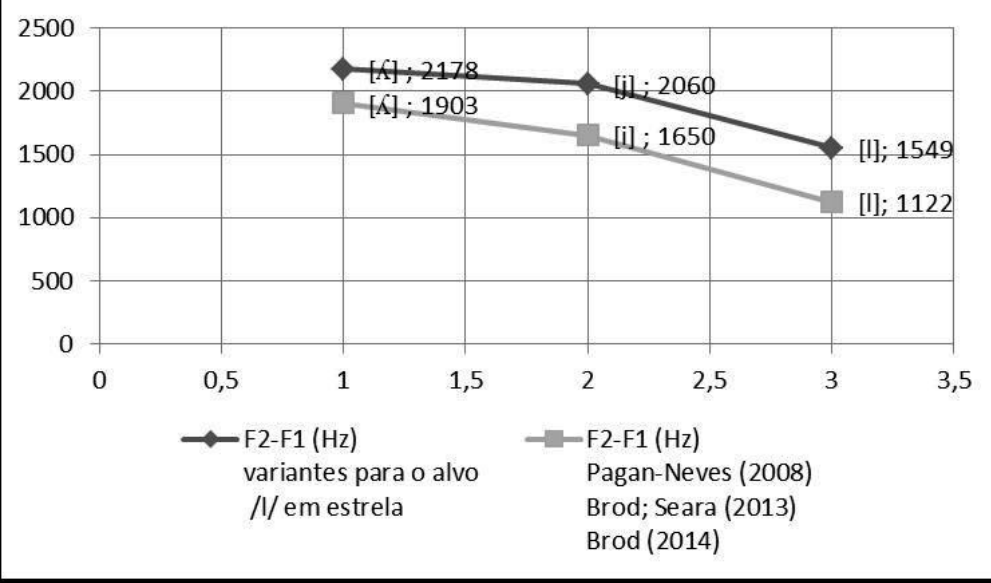

Fonte: próprio autor.

Agora, voltando à Tabela 5, verifica-se, pelos valores de F1 e F2, a presença das vogais, referentes aos casos de substituição (semivocalização). Pela Tabela 5, percebe-se que os valores de F1 e F2 ratificam as variantes etiquetadas. A variante ['ejle] apresenta valores de F2 bem mais altos do que os esperados para a presença de uma lateral. Isso pode ser justificado pela presença concomitante de uma semivogal anterior [j] que tem valores bastante altos de F2 e que, provavelmente, coarticulatoriamente levou a esse valor mais elevado de F2 na lateral alveolar. O que nos assegura que esses valores mais altos são efeitos de coarticulação da vogal precedente é o clareamento observado no espectrograma na região identificada como a lateral. Esse clareamento indica menor intensidade na região que evidencia a lateral alveolar em comparação as regiões adjacentes ocupadas por sons vocálicos. Observe a Figura 7 (Seção 6.1). Dessa maneira, pelas análises, qualitativa e quantitativa, é ratificada a presença da variante ['ejle].

\section{Considerações finais}

Este artigo visou a analisar a emergência da líquida lateral /1/ na fala de uma criança acompanhada longitudinalmente entre 1:9 e 2:4. Para 
isso, foram investigadas as produções do vocábulo estrela realizadas pelo infante, procurando identificar variações na fala do sujeito investigado na tentativa de aproximar-se da palavra-alvo.

De início, focalizou-se a análise de oitiva, ensejo em que levou a observação de cinco variantes da palavra /eS'trela/ empregadas pela

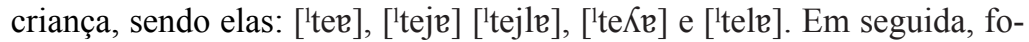
ram feitas inspeções visuais no sinal de fala para ratificar as etiquetagens de oitiva. Para verificação acústica da diferença entre cada variante para $\mathrm{o}$ alvo /1/, investigou-se a diferença entre F2-F1, haja vista que essa parece ser uma forma bastante adequada de mensurar o grau de posteriorização da lateral e, consequentemente, verificar a presença de gradiências nas produções de /1/ realizadas para o alvo estrela.

Com base nesses resultados, constatou-se que, quando a diferença entre F2-F1 diminui, as produções se aproximaram do alvo - a lateral alveolar. Esses achados foram corroborados pelos estudos de Pagan-Neves (2008), Brod e Seara (2013) e Brod (2014).

Neste particular, entretanto, vale salientar que as diferenças resultantes entre F2-F1 deste estudo foram consideravelmente maiores do que as verificadas em Pagan-Neves (2008), Brod e Seara (2013) e Brod (2014). Sem embargo, a trajetória decrescente que os valores de F2-F1 apontaram - iniciando mais alto para a lateral palatal e tendo seu valor mais baixo para a lateral alveolar — foram bastante similares aos apontados pela literatura.

Assim, concluiu-se que os resultados verificados neste estudo foram corroborados pelos dados de Pagan-Neves (2008), Brod e Seara (2013) e Brod (2014). Mister reforçar, de todo modo, que um corpus com mais informantes na faixa etária estudada revela-se essencial para ulteriores inferências confirmatórias. 


\title{
THE EMERGENCE OF THE LIQUID CONSONANT /1/ IN A CHILD'S SPEECH: A LONGITUDINAL STUDY
}

\begin{abstract}
In this work it is investigated quantitative and qualitatively the emergence of liquid consonant /1/ in a child's speech in Brazilian Portuguese as their L1, which was longitudinally observed between 1:9 (one year and nine months) and 2:4 (two years and four months). In order to do so, thirty-four productions related to the word /eS'trela/ were analyzed and five variants of execution were verified, namely: ['tee $],\left[{ }^{1}\right.$ teje $]\left[{ }^{1}\right.$ tejle $]$, ['te $\left.K \mathfrak{e}\right]$ and ['tele]. Each of these variants was analyzed qualitatively based on the trajectory of the formants and the intensity of the sounds showed by the spectrograms; and quantitatively, through the analysis of the values of formants' frequencies and especially by the difference between F2 and F1, necessary to verify the degree of posteriorization of the lateral produced. From the analyzes, gradients were observed in the subject's speech in an attempt to reach the target - the lateral alveolar. These gradients could only be verified on the basis of the acoustic analyzes detailed here. Values resulting from the difference between F2-F1 revealed that the distance between the two subjects decreased as productions approached their target because it was verified that when the difference between these two formants decreases the productions approach the lateral alveolar. KEYWORDS: Phonetics. Phonology. Language acquisition.
\end{abstract}

Agradecimentos

Ao CNPQ, pela bolsa de produtividade.

Aos pareceristas desta Revista, pela leitura rigorosa e pelos comentários ao texto original que certamente contribuíram para uma versão mais adequada do artigo. Salientamos, no entanto, que as inadequações remanescentes são de nossa inteira responsabilidade. 


\section{NOTAS}

${ }^{1}$ Este software pode ser obtido livremente no endereço: $\underline{\text { www.ocenaudio.com. }}$

${ }^{2}$ Agradecemos a Fernando Santana Pacheco pela elaboração do script para coleta dos valores dos dois primeiros formantes em cinco pontos equidistantes dentro do som-alvo.

${ }^{3}$ Caso o valor coletado no ponto 3 apresentasse alguma inconsistência, eram considerados os valores exibidos pelos pontos 2 ou 4 , já que esses pontos também se encontravam na região mais estável dos sons-alvo.

${ }^{4}$ Nesta tabela, não constam os resultados referentes à variante ['tee], uma vez que a estratégia de reparo utilizada nessa produção foi a omissão da lateral-alvo.

${ }^{5}$ Em função do pouco número de dados, não foi possível realizar estatísticas inferenciais (testes de diferenças) para a observação de diferenças entre os grupos de segmentos aqui caracterizados.

\section{REFERÊNCIAS}

AZAMBUJA, E. J. A aquisição das líquidas laterais do português. 1998. Dissertação (Mestrado em Letras) - Instituto de Letras e Artes, PUCRS, Porto Alegre, 1998.

BERTI, L. C. Aquisição incompleta do contraste entre /s/ e /S/ em crianças falantes do português brasileiro. 2006. Tese (Doutorado em Letras) - Instituto de Estudos da Linguagem, Universidade Estadual de Campinas, Campinas, 2006. ; Contrastes e contrastes encobertos na produção da fala de crianças. Pró-Fono Revista de Atualização Científica, v. 22, n. 4, 2010.

; MARINO, V. C. C. Contraste fônico encoberto entre /t/ e /k/: um estudo de caso de normalidade e de transtorno fonológico. Revista CEFAC, São Paulo, v.13, n.2, 2011.

BONINI, J. B. Aquisição e ambientes favorecedores das líquidas no desvio fonológico. 2012. Dissertação (Mestrado em Distúrbios da Comunicação Humana) - Universidade de Santa Maria, Santa Maria (RS), 2012.

BOERSMA, P.; WEENINK, D. Praat: doing phonetics by computer, v. 5.1. Disponível em: <http://www.praat.org>, acesso em: 12 fev. 2017.

BRAGA, J. N.; OLIVEIRA, D.S.F.; SAMPAIO, T.M.M. Frequência fundamental da voz de crianças.Revista CEFAC, São Paulo, v.11, n.1, p. 119-126, jan./mar. 2009. 
BROD, L. E. M. A lateral nos falares florianopolitano (PB) e portuense (PE): casos de gradiência fônica. 2014. Tese (Doutorado em Linguística) Programa de Pós-Graduação em Linguística, Universidade Federal de Santa Catarina, Florianópolis, 2014.

BROD, Lilian E. M., SEARA, Izabel C. As vogais orais do português brasileiro na fala infantil e adulta. Linguagem \& Ensino, Pelotas, v. 16, n. 1, p. 111-130, jan/jul. 2013.

BROWMAN, C. P.; GOLDSTEIN, L. Articulatory gestures as phonological units. Phonology Yearbook. p. 201-251, 1989.

CEMIM, J. Aquisição do contraste de "vozeamento": um estudo longitudinal. 2014. Tese (Doutorado em Linguística) - Programa de Pós-Graduação em Linguística, Universidade Federal de Santa Catarina, Florianópolis, 2014.

CRISTOFOLINI, C. Gradiências e contrastes encobertos na fala infantil: caracterizações acústico-articulatória e perceptual de segmentos plosivos e fricativos. 2013.Tese (Doutorado em Linguística) - Programa de Pós-graduação em Linguística, Universidade Federal de Santa Catarina, Florianópolis, 2013.

LAMPRECHT, R. R. etal. Aquisição fonológica do português: perfil de desenvolvimento e subsídios para terapia. Porto Alegre: Artes Médicas, 2004.

LAZZARotTO-VOLCÃO, C. Modelo Padrão de Aquisição de Contrastes: uma proposta de avaliação e classificação dos desvios fonológicos. 2009. Tese (Doutorado). Universidade Católica de Pelotas, Pelotas, 2009.

LINDBLOM, B. E. F.; SUNDBERG, J. E. F. Acoustical consequences of lip, tongue, jaw, and larynx movements. Journal of the Acoustical Society of America, 50, p.1166-1179, 1971.

MARQUES, T. F. Aquisição do português brasileiro em gêmeos dizigóticos. 2016. Dissertação (mestrado em linguística), Programa de Pós-Graduação em Linguística, Universidade Federal de Santa Catarina. Florianópolis, 2016.

MATZENAUER-HERNANDORENA, C.L. Aquisição da fonologia do português: estabelecimento de padrões com base em traços distintivos. 1990. Tese (Doutorado) - Pontifícia Universidade Católica (RS), Porto Alegre, 1990.

; LAMPRECHT, R. R. A aquisição das consoantes líquidas do português. Letras Hoje, Porto Alegre, v. 32, n. 4, p. 7-22, dez. 1997.

MEZZOMO, C. L.; RIBAS, L. P. Sobre a aquisição das líquidas. In. LAMPRECHT, Regina R. (Org.). Aquisição fonológica do português: perfil de desenvolvimento e subsídios para terapia. Porto Alegre: Artes Médicas, p. 95-112, 2004.

OLIVEIRA, F. R. M. Análise acústica de sequências de fricativas seguidas de [i] produzidas por japoneses aprendizes de português brasileiro. In: IX Encontro do 
CELSUL, 2010, Palhoça. Anais... Palhoça (SC), 2010, p 10-11.

PAGAN-NEVES, L. O. Descrição acústico-articulatória e perceptiva das líquidas do português brasileiro produzidas por crianças com e sem transtorno fonológico. 2008. Tese (Doutorado em Linguística e Semiótica Geral) - Universidade de São Paulo, São Paulo, 2008.

SILVA, A. H. P. Para a Descrição Fonético-Acústica das Líquidas no Português Brasileiro: dados de um informante paulistano. 1996. Dissertação (Mestrado em Linguística) - Instituto de Estudos da Linguagem, Universidade Estadual de Campinas, Campinas, 1996.

SILVA, A. H. P. As fronteiras entre Fonética e Fonologia e a alofonia dos róticos iniciais em PB: dados de dois informantes do sul do país. 2002. Tese (Doutorado) - Universidade de Campinas/IEL/LAFAPE, Campinas, 2002.

STEVENS, K. N. Vowels: acoustic Eventswith a Relatively Open Vocal Tract. Acoustic Phonetics. Cambridge, 2000.

VANZELLA T. H. Normatização dos parâmetros acústicos vocais em crianças em idade escolar. 2006. Dissertação (Mestrado) - Universidade de São Paulo, Ribeirão Preto (SP), 2006.

VAZ, R. M. O contraste encoberto de vozeamento em um caso de desvio fonológico. 2010. Dissertação (Mestrado) - Programa de Pós-graduação em Letras. Pontifícia Universidade Católica de Pelotas, Pelotas, 2010.

Recebido em: 30/04/2017

Aceito em:20/07/2017 